\title{
A study of pain threshold in diabetics with neuropathic foot lesions
}

\author{
PAMELA M LE QUESNE, CLARE J FOWLER \\ From the Department of Neurological Studies, The Middlesex Hospital Medical School, London and Medical \\ Research Council Toxicology Unit, Carshalton, Surrey, UK
}

SUMMARY Pain thresholds to a pinch stimulus were measured at eight sites on the dorsum of both feet from 17 diabetic patients. Sixteen feet had neuropathic ulcers and seven had Charcot arthropathy. Vibration perception thresholds, radial nerve action potentials, muscle action potentials of flexor digitorum brevis, autonomic cardiovascular reflexes and reflex sweat output were also measured. Pinch pain threshold was abnormal in 15 diabetic feet, 11 having one or more insensitive sites. There was a greater variability in threshold between sites tested in diabetic than control subjects.

Foot lesions are a major cause of morbidity in diabetics. Various types of disorder may occur: ischaemic lesions due to large vessel disease, Charot arthropathy and neuropathic ulceration. In the latter two conditions sensory neuropathy is thought to be a major aetiological factor, although the contributory importance of muscle weakness, autonomic denervation, small vessel angiopathy, glycosylation of tissue proteins and poor response to infection is increasingly recognised. ${ }^{1}$

In many types of peripheral neuropathy large diameter nerve fibres are predominantly affected. However, in diabetic neuropathy small diameter fibres are particularly liable to be involved, that is, those subserving temperature, autonomic function and pain appreciation. Severe involvement of small diameter fibres has been demonstrated pathologically in selected cases. ${ }^{2}$ Autonomic denervation is common in diabetics with neuropathic foot lesions, ${ }^{34}$ and Guy et al $^{5}$ have found that temperature appreciation (subserved by Ad and $\mathrm{C}$ fibres) is more frequently abnormal than vibration perception threshold (large $\mathbf{A b}$ fibre function) in diabetic neuropathy.

Reduced appreciation of noxious stimuli (related to

Address for reprint requests: Dr PM Le Quesne, The Middlesex Hospital Medical School, London WIN 8AA, UK.

Received 22 October 1985 and in revised form 7 January 1986. Accepted 13 January 1986
Ad and C fibres) predisposes to neuropathic ulceration and to Charot arthorpathy because of the cumulative destructive effect of unrecognised minor trauma. The present study was undertaken to determine whether pain produced by a skin pinch is abnormal in diabetics with neuropathic foot lesions and to assess whether pinch pain threshold might be a useful measure of small fibre neuropathy. This measurement has been compared with other nerve function tests: sensory nerve and muscle action potentials, vibration perception threshold and some autonomic function tests.

\section{Patients and methods}

\section{Subject}

Both feet of 20 healthy subjects, aged 18-24, were examined. Thirty two feet from 17 diabetic patients, aged 39-68 (mean $53 \pm 8.0$ years), attending The London Foot Hospital were studied. Sixteen feet had neuropathic ulcers (eight active, eight healed), seven had Charot arthropathy and nine had neither type of lesion.

\section{Pain threshold}

Pain threshold was measured with a "pinchometer" built by Dr Bruce Lynn, Department of Physiology, University College, London, and previously described by Lynn and Perl. ${ }^{6}$ Skin folds were pinched between the flat plates of a pair of forceps (area $16 \mathrm{~mm}^{2}$ ). Force was transmitted by means of a stiff spring to a pair of silicon strain gauges. The skin was pinched at a uniform rate until the subject signalled that 


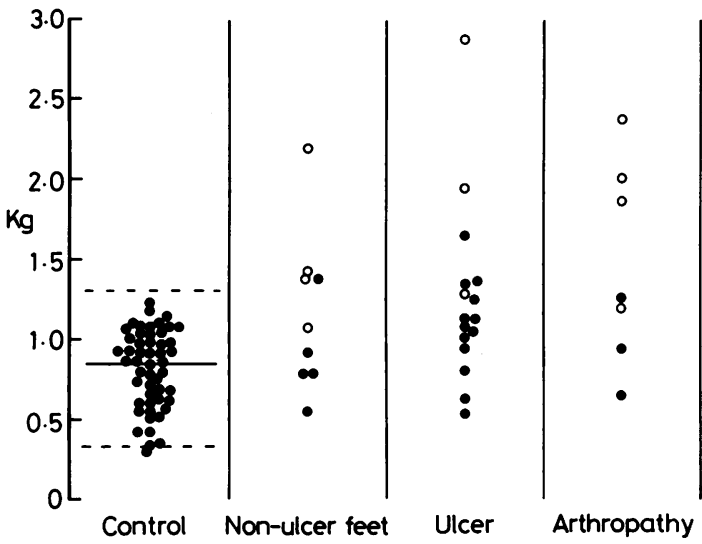

Fig 1 Pain threshold for control subjects and different groups of diabetic patients. Closed circles are mean values for 8 points tested. Open circles are patients with one or more insensitive points. Solid bar is mean value for control subjects and dotted lines are $2 S D$ from mean.

pain was felt. The peak force was held on the dial and read.

The standard procedure was to pinch the skin on the dorsum of the foot at eight separate points. To avoid tissue damage the maximum force applied to the forceps was $2.7 \mathrm{~kg}$. The mean value and standard deviation were calculated and the number of insensitive points recorded.

\section{Vibration sensation}

Vibration sensation threshold was measured in all feet with a Bio-thesiometer (Ohio Instrument $\mathrm{Co}$ ) by gradually increasing the amplitude from zero at a constant rate. The subject reported when vibration was first felt. Control data from 44 healthy subjects, aged 40-79 (mean $54 \pm 7.9$ years), was used for comparison. ${ }^{\text {? }}$

\section{Electrophysiology}

The peak to peak amplitude of the sensory nerve action potential, recorded orthodromically through surface electrodes from the superficial radial nerve, was measured in 15 of the 17 diabetics. Control values were obtained from 24 subjects of similar age.

The evoked muscle action potential was recorded from flexor hallucis brevis on the sole of 22 diabetic feet following stimulation of the posterior tibial nerve at the ankle. The amplitude of the negative deflection above the base line was measured and compared with values for 17 control feet. Temperature on the foot was always at least $29^{\circ} \mathrm{C}$.

\section{Autonomic function}

Two tests of cardiovascular autonomic function (heart rate response to Valsalva manoeuvre and to a single deep breath) were carried out on 14 diabetics (related to $28 \mathrm{feet}$ ). For the Valsalva ratio a value of less then 1.2 was taken as abnormal and for the deep breath an expiratory-inspiratory difference of less than 10 beats/min was considered abnormal. ${ }^{8}$ For statistical comparison data from 30 healthy subjects, aged 40-70 (mean $54 \pm 7.5$ years), were used.
The volume of sweat produced by axon reflex stimulation following electrophoresis of acetylcholine ${ }^{910}$ was measured in 19 feet.

\section{Results}

In the control subjects mean pinch pain threshold was $0.84 \mathrm{~kg}$ (SD: 0.24 ) (fig 1). No insensitive points were found. There was no correlation between age and pain threshold (correlation coefficient $r=0.04 \mathrm{p}>$ 0.05 ). To assess the variability in threshold at different sites the standard deviation of the individual observations was calculated for each subject. The mean value was $0 \cdot 21 \mathrm{~kg}$ (SD: $0 \cdot 11)$.

The mean pinch pain threshold for the diabetic subjects was significantly higher $(1.22 \mathrm{~kg}$; SD: 0.47$)$ than for control subjects ( $p<0.001)$. Fifteen feet were abnormal; in four mean threshold was raised although all points were sensitive. In 11 feet there were one or more insensitive points, all points being insensitive in one subject. In seven with insensitive points, mean threshold for the other points was raised, whereas in three it was within the control range. Thresholds in the different groups of diabetics are shown in fig 1 .

There was more variation in pain threshold for the different sensitive points on the foot in the diabetics (mean standard deviation $0.37 \mathrm{~kg}$; SD: 0.21 ) than in the control feet $(0.21 \mathrm{~kg}$; SD: 0.11$)(\mathrm{p}<0.001)$. The findings in one patient with a typical neuropathic ulcer are shown in fig 2 . There was a marked variation in threshold at different sites; two were insensitive and one had an abnormally low threshold. When pinched at two other sites, pain was felt over an area remote from the pinch. This latter observation was also noted in three other diabetic feet. One of these, with arthropathy, had only one sensitive point which, when pinched, produced a long persistent sting $3 \mathrm{~cm}$ away. In another two feet, a burning or more severe persistent pain, rather than the usual brief sharp prick, occurred on pinching one point.

In the ulcer group, the mean threshold was the same in those with active ulcers $(1 \cdot 1 \mathrm{~kg})$ and those with healed ulcers $(1 \cdot 1 \mathrm{~kg})$. There was a higher incidence of insensitive points in feet with arthropathy (four of seven feti) than with an ulcer (three of 16 feet).

Vibration perception threshold was within the control range in six diabetic feet (two with no ulcer or arthropathy, four with an ulcer, but none with arthropathy). There was a highly significant difference in vibration threshold between control subjects $(1 \dot{4} .8 \pm 6.70$ Bio-thesiometer units $)$ and diabetics $(41 . \overline{4} \pm 16.41$ units $)(\mathrm{p}<0.001)$ but not significant differences between the various diabetic groups (table). 


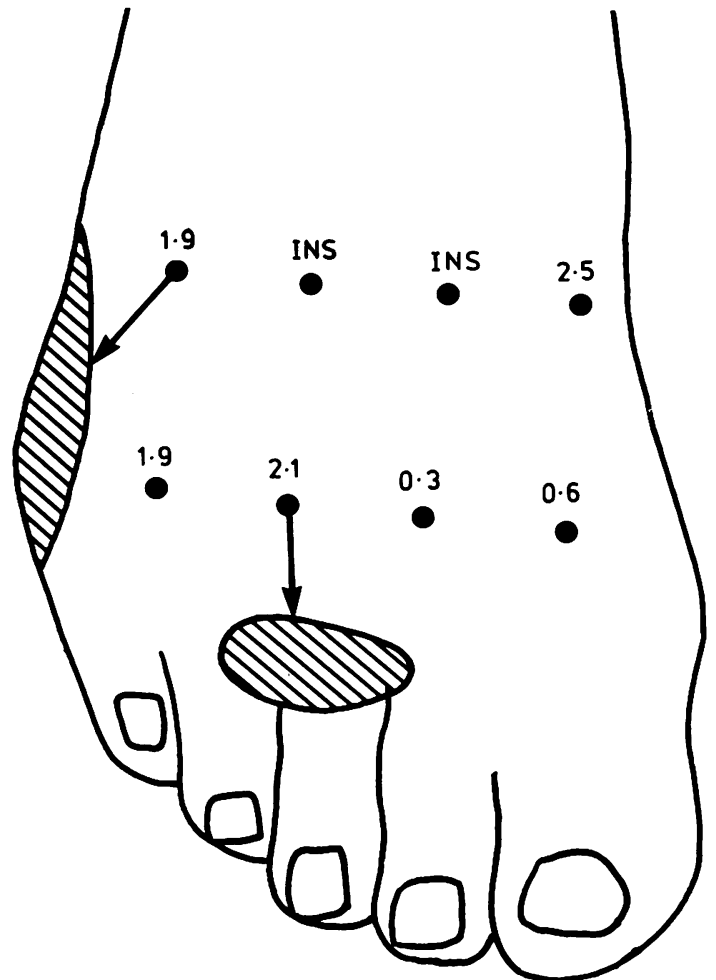

Fig 2 Pain threshold at different sites on dorsum of foot of a patient with severe diabetic neuropathy and foot ulceration. INS-no pain felt at $2 \cdot 7 \mathrm{~kg}$. Arrows to shaded areas indicate referral of pain from point tested.

The amplitude of the radial nerve action potential was significantly smaller in the diabetics than in control subjects $(p<0.001)$ but there was no difference between the different diabetic groups. The radial nerve action potential was abnormal in 14 of the 16 subjects tested. Likewise, the amplitude of the muscle response from flexor hallucis was significantly smaller in the diabetics compared with controls $(p<0.001)$.
Amplitude was below the lower range of normal in all except one of the 22 feet examined.

One or both cardiovascular reflexes were abnormal in all diabetics except one with bilateral ulcers, but there were no significant differences between the different diabetic groups (table). The higher incidence of absent sweating in the ulcer compared with the arthropathy group (table) has been described and discussed in a previous study. ${ }^{10}$

\section{Discussion}

This study confirms that many aspects of nerve function are abnormal in diabetics with neuropathic foot lesions. Involvement of large nerve fibres was shown by abnormalities in electrophysiological tests and vibration perception threshold in most subjects. Autonomic disturbances were demonstrated by defective cardiovascular reflexes and the high incidence of absent sweating.

It is, perhaps, surprising that cutaneous pinch pain threshold was not abnormal in a higher number, since pain loss is usually considered to be important in the aetiology of foot lesions. One factor may be that pain loss is patchy. It is recognised clinically that part of a diseased foot may be painlessly removed without anaesthesia whereas only a few centimetres proximally the foot remains sensitive. Indeed variability of response to pinch was the most readily demonstrated evidence of abnormal pain appreciation. So much so that about one-third of feet tested had one or more points where the maximum force used $(2.7 \mathrm{~kg})$ did not produce pain.

Patients' description of the sensation produced by pinch allows one to make some speculative suggestions as to the underlying pathology. Variability of threshold with some insensitive areas suggests patchy loss of nerve fibres, referral of pain to a different site suggests that collateral sprouting or faulty reinnervation may have occurred. Abnormally sensitive areas may be related to immature regenerating fibres or sprouts. The subjective quality of a dull or burning pain occasionally reported may be due to stimulation

Table Nerve function tests in control and different groups of diabetic subjects, mean $\pm S D$

\begin{tabular}{|c|c|c|c|}
\hline No ulcer or arthropathy & Ulcer & Arthropathy & Control \\
\hline 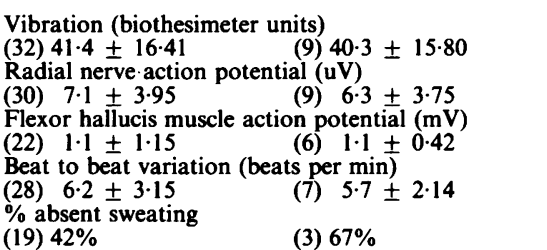 & $\begin{array}{l}\text { (16) } 40.1 \pm 19.59 \\
\text { (16) } 7.0 \pm 3.54 \\
\text { (12) } 1.4 \pm 1.41 \\
\text { (14) } 7.0 \pm 3.86 \\
\text { (10) } 50 \%\end{array}$ & $\begin{array}{l}\text { (7) } 45.7 \pm 8.36 \\
\text { (5) } 8.8 \pm 5.73 \\
\text { (4) } 0.2 \pm 0.29 \\
\text { (7) } 5.1 \pm 2.19 \\
\text { (6) } 17 \%\end{array}$ & $\begin{array}{l}\text { (44) } 14.8 \pm 7.7 \\
\text { (24) } 24.0 \pm 11.1 \\
\text { (17) } 7.8 \pm 3.1 \\
\text { (30) } 22.2 \pm 7.6 \\
\text { (35) } 0 \%\end{array}$ \\
\hline
\end{tabular}

Figures in parentheses are numbers of subjects tested. 
of endings innervated by $\mathrm{C}$ fibres rather than the high threshold mechanoreceptors supplied by Ad fibres which are responsible for sharp pain in control subjects.

We conclude from this study that measurement of pinch pain threshold on the dorsum of the foot may give qualitative information about disturbances in pain pathways. However, it is of limited value as a quantitative measure of small nerve fibre dysfunction. Measurement of threshold to temperature change, recently reported to be abnormal in many diabetics by Guy et al $^{5}$ may be more valuable. We are currently measuring separately threshold to warming (dependent on unmyelinated fibres) and to cooling (related to Ad fibres) in these patients.

We are grateful to Dr Bruce Lynn for building the pinchometer and for helpful discussions and to The Sir Jules Thorn Charitable Trust for a grant from which the apparatus was bought. We would also like to thank Dr A Kurtz, The Middlesex Hospital and Mr K Robertson, The London Foot Hospital for allowing us to investigate patients under their care and Mr ME Ahmed for assistance in selecting the patients and for carrying out the autonomic tests.

CJF is grateful for the support of Ipsen-Beaufour International while this work was carried out.
References

${ }^{1}$ Delbridge L, Ctercteko G, Fowler C, Reeve TS, Le Quesne LP. The aetiology of diabetic neuropathic ulceration of foot. Br J Surg 1985;72:1-6.

${ }^{2}$ Said G, Slama G, Selva J. Progressive centripetal degeneration of axons in small fibre diabetic polyneuropathy. A clinical and pathological study. Brain 1983;106: 791-807.

${ }^{3}$ Ward JD. The diabetic leg. Diabetologia 1982;22:141-7.

${ }^{4}$ Watkins PJ, Edmonds ME. Sympathetic nerve failure in diabetes. Diabetologia 1983;25:73-7.

${ }^{5}$ Guy RJC, Clark CA, Malcolm PN, Watkins PJ. Evaluation of thermal and vibration sensation in diabetic neuropathy. Diabetologia 1985;28:131-7.

${ }^{6}$ Lynn B, Perl ER. A comparison of four tests for assessing the pain sensitivity of different subjects and test areas. Pain 1977;3:353-65.

${ }^{7}$ Le Quesne PM, Fowler CJ. (In press).

${ }^{8}$ A hmed ME, Delbridge L, Le Quesne LP. The role of autonomic neuropathy in diabetic foot ulceration. $J$ Neurol Neurosurg Psychiatry (in press).

${ }^{9}$ Low PA, Caskey PE, Tuck RR, Fealey RD, Dyck PJ. Quantitative sudomotor axon reflex test (Q-SART). Ann Neurol 1983;14:573-80.

${ }^{10}$ Ahmed ME, Le Quesne PM. Quantitative sweat test in diabetics with neuropathic foot lesions. J Neurol Neurosurg Psychiatry (in press). 